\title{
Solvent Extraction ICP-MS/MS Method for the Determination of REE Impurities in Ultra-high Purity Ce Chelates
}

\author{
Yan Zhang*,a, Zhongben Pan ${ }^{\mathrm{a}}$, Pengchong Jiao ${ }^{\mathrm{a}}$, Jia Ju ${ }^{\mathrm{a}}$, Ting $\mathrm{He}^{\mathrm{a}}$, \\ Taicheng Duan*, b, and Huaqiang Cai*,a \\ a Institute of Chemical Materials, China Academy of Engineering Physics, \\ No.64 Mianshan Road, Mianyang 621900, P.R. China \\ b State Key Laboratory of Electroanalytical Chemistry, Changchun Institute of Applied Chemistry,
}

\section{ABSTRACT}

This paper describes a new method for the determination of trace rare earth elements (REEs) in cerium chelates of extremely high purity by triple quadruple inductively coupled plasma mass spectrometry (ICP-MS/MS) after solvent extraction. Based on the outstanding performance of ICPMS/MS, interferences on $\mathrm{La}, \mathrm{Pr}$, $\mathrm{Tb}, \mathrm{Gd}$, and $\mathrm{Yb}$ were reduced by 2 3 orders of magnitude in comparison with ICP-QMS. Further, chemical separation employing solvent extraction using Cyanex ${ }^{\circledR}$ 272 (bis(2,4,4-trimethylpentyl) phosphinic acid) was carried out, and about $99.95 \%$ of the $\mathrm{Ce}$ matrix, after being digested and oxidized to $\mathrm{Ce}^{4+}$ with $\mathrm{KMnO}_{4}$, could be removed, with recoveries for all of the 14 REEs ranging from $92.8 \%$ to $103 \%$. Key factors that influenced the separation effects, such as the extraction

\section{INTRODUCTION}

The Chelate Precursor Doping Technique (CPDT) based on volatile rare earth element (REE) organic chelates is a promising technique for high-power-laser fiber preparation. In comparison with the traditional inorganic REE halides-based techniques $(1,2)$, it can realize element doping with higher concentrations. The tetrakis(2,2,6,6-tetramethyl-3,5-heptanedionato) cerium(IV) chelate

\footnotetext{
*Corresponding authors.

E-mail: zhang_yan@caep.cn

E-mail: tcduan@ciac.ac.cn

Tel: + 86-13880610848

Tel: $+86-02865726197$
}

acidity and time, the amount of $\mathrm{KMnO}_{4}$, the back-extraction acidity and time, were systematically studied and optimized. The established new separation procedure showed great superiority over the reported EHEHP (2-ethylhexyl hydrogen-2-ethylhexylphosphonate) based method in terms of conciseness in operation, low acidity for back-extraction, and high matrix separation efficiency. Thus, with the combination of chemical and physical high efficiency separation of the matrix-induced interferences, truly interference-free determination was realized, together with high analytical sensitivity and detection limits $(3 \sigma)$ for the 14 REEs ranging from $0.013 \sim 0.44$ $\mathrm{ng} \mathrm{g}^{-1}$. The proposed new method was also verified by using three real samples for batch analysis of cerium chelates up to $7 \mathrm{~N}$ purity.

$\left(\mathrm{Ce}(\mathrm{TMHD})_{4}\right)$ is a very effective gas phase doping source of cerium for the function of reducing the darkening effect and improving power stability (3), which is extremely important for the development of laser fibers capable of ultra-high energy transmission. In order to minimize the risk of energy loss caused by the long optical path of the fiber, the purity of the REE chelates is usually required to be as high as possible, thus techniques effective for the accurate determination of REE impurities at ultralow levels are essential $(4,5)$.

It is well known that the determination of ultra-trace REE impurities in high-purity cerium compounds is of great challenge. Due to the severe optical spectra interferences and relatively low sensitivity, inductively coupled plasma optical emission spectroscopy (ICP-OES) is not recommended for application in the direct analysis of samples with a purity over $4 \mathrm{~N}$ (6-8); while for inductively coupled plasma quadrupole mass spectrometry (ICP-QMS), matrix Ce induced mass spectra interferences on $\mathrm{La}, \mathrm{Pr}, \mathrm{Tb}, \mathrm{Gd}$, and Dy make it impossible for the direct analysis of samples with a purity over $5 \mathrm{~N}$ (9).

In recent years, a new inorganic mass technique, named triple quadrupole inductively coupled plasma mass spectrometry (ICPMS/MS), has demonstrated to be a good choice for the direct analysis of REE samples with ultra-low impurity content (10). In comparison with ICP-QMS, the mass screening function of the additional quadrupole mass filter in front of the collision/reaction system can greatly increase the power of polyatomic interference elimination $(11,12)$, which was well proved by the direct analysis of $6 \mathrm{~N} \mathrm{Nd}_{2} \mathrm{O}_{3}$ and $\mathrm{Sm}_{2} \mathrm{O}_{3}(13,14)$. However, for REE samples with an even higher purity as $7 \mathrm{~N}$, especially for cerium compounds, there has up to now been no data available using ICP-MS/MS for direct analysis.

Of course, when the instrumental resolution is not sufficient, chemical separation of the matrix is then necessary, and usually solid phase chromatographic separation or solvent extraction separation is mostly adopted for this purpose (15-17). By comparison, the latter 
has the merits of better conciseness in operation, higher sample throughput and most importantly, enrichment ability for the analytes, which is particularly desirable for ultratrace analysis due to improvement in analytical sensitivity. The reason for recommending solvent extraction in Ce matrix separation is that Ce(III) can be easily oxidized to Ce(IV), which shows a much stronger affinity with some phosphinic acidic extractants, typically EHEHP (2-ethylhexyl hydrogen-2ethylhexylphosphonate), than the REE(III) impurities, thus high matrix separation efficiency can be easily obtained.

A perfect example for $6 \mathrm{~N}$ purity $\mathrm{CeO}_{2}$ analysis by ICP-QMS was reported by Li et al. (17), though mathematical correction was additionally needed for the elimination of residual mass interferences, and matrix separation efficiency up to 99.5\% was accomplished. However, the EHEHP extractant also has a relatively strong affinity with heavy REE(III) ions, thus two back-extraction steps employing relatively high concentrations of acidic solutions were required for satisfactory recoveries of all of the REE analytes. In addition, the obtained backextraction aqueous solution must be evaporated to small volumes for acidity reduction and analyte enrichment, which inevitably damages the conciseness of the whole analytical procedure. Fortunately, a relatively new acidic organophosphorous extractant, Cyanex 272 (bis(2,4,4-trimethylpentyl) phosphinic acid), had been developed to overcome the problem with EHEHP. Since it had much weaker affinity with heavy REE(III) ions, back-extraction might be carried out at lower concentrations of acidic solutions and at a reduced frequency $(18,19)$. For analytical use, Cyanex 272 has been applied to prepare adsorption resin minicolumns for on-line or off-line chromatographic separation of REE(III) ions prior to ICP-OES or ICP-MS analysis of some REE oxides with a purity of $5 \mathrm{~N}$ (20).

In this work, we aimed to develop a robust method for rapid, concise, high sensitive, and interference-free determination of ultratrace REE impurities in Ce(TMHD) with an extremely high purity of 7N. ICP-MS/MS was employed for analyte detection, while Cyanex 272 was adopted for solvent extraction separation of the matrix. To our knowledge, no similar work has been previously reported.

\section{EXPERIMENTAL}

\section{Instrumentation}

For this study, an Agilent $^{\circledR} 8800$ triple quadrupole ICP-MS (ICPMS/MS) (Agilent Technologies, USA) was used, equipped with $\mathrm{x}$-lens and Ni cones, a MicroMist glass concentric nebulizer, a Peltiercooled quartz double-pass Scotttype spray chamber and a quartz torch with a $2.5 \mathrm{~mm}$ i.d. injector. The ICP-MS/MS also features a high matrix introduction (HMI) aerosol dilution device for reducing the total sample load into the plasma. The instrumental parameters are listed in Table I.

Reagents, Standard Solutions, and Equipment

Deionized water $(18.2 \mathrm{M} \Omega \cdot \mathrm{cm})$, obtained from an ELGA PURELAB Ultra water purification system (England), was used to prepare all solutions. Nitric acid (ultrapure grade, ULTREX ${ }^{\circledR}$ II, J. T. Baker, USA) was used to digest the samples. A multi-element standard stock solution containing $10 \mathrm{mg} \mathrm{L}^{-1}$ of $\mathrm{Y}, \mathrm{La}$, Pr, Nd, Sm, Eu, Gd, Tb, Dy, Ho, Er, $\mathrm{Tm}, \mathrm{Yb}, \mathrm{Lu}$, and a single-element standard stock solution containing $1000 \mathrm{mg} \mathrm{L}^{-1}$ of Cs (National Center for Analysis and Testing of Nonferrous Metals and Electronic Materials, Beijing, P.R. China) were used to prepare the calibration standard solutions and the internal standard solution by stepwise dilution with $2 \%$ (v/v) $\mathrm{HNO}_{3}$. All utensils used for the solutions were made of PFA material and prior to use, they were soaked overnight in 30\% nitric acid, then washed repeatedly with deionized water.

Cyanex 272 (90\%, Cytec Industries Inc., Canada) was used as the extractant and cyclohexane (ultrapure grade, Sigma-Aldrich, Germany) was used as the diluent. Working solutions were prepared by mixing Cyanex 272 with cyclohexane to give about a $0.05 \mathrm{~mol} \mathrm{~L}^{-1}$ concentration, and purified by repeated backextraction with $10 \%(\mathrm{v} / \mathrm{v}) \mathrm{HNO}_{3}$. Acetic acid-acetate buffer solution $(\mathrm{pH}=4)$, monochloroacetic acid buffer solution ( $\mathrm{pH}=3$ ), and $\mathrm{KMnO}_{4}$ solution $\left(5.0 \mathrm{~g} \mathrm{~L}^{-1}\right)$ were prepared with analytical grade chemicals.

$\mathrm{Ce}(\mathrm{TMHD})_{4}$ of $7 \mathrm{~N}$ purity was homemade.

\section{Sample Digestion}

A $0.1000 \mathrm{~g}$ amount of highpurity $\mathrm{Ce}(\mathrm{TMHD})_{4}$ was digested using $1.0 \mathrm{~mL} \mathrm{HNO}_{3}$ in a PFA closed vial at $120{ }^{\circ} \mathrm{C}$ for 30 minutes until a clean sample solution was obtained. After cooling, the solution was transferred to the volumetric flask and adjusted to $50 \mathrm{~mL}$ with $2 \%(\mathrm{v} / \mathrm{v}) \mathrm{HNO}_{3}$.

TABLE I ICP-MS/MS

Operating Parameters

\begin{tabular}{lr}
\hline Parameters & \multicolumn{1}{c}{ Values } \\
\hline Plasma RF power & $1550 \mathrm{~W}$ \\
Sampling depth & $8.0 \mathrm{~mm}$ \\
Carrier gas flow rate & $0.6 \mathrm{~L} \mathrm{~min}^{-1}$ \\
Dilution gas flow rate & $0.5 \mathrm{~L} \mathrm{~min}^{-1}$ \\
Extract 1 voltage & $0.0 \mathrm{~V}$ \\
Extract 2 voltage & $-70.0 \mathrm{~V}$ \\
Omega voltage & $8.0 \mathrm{~V}$ \\
Omega Bias voltage & $-60.0 \mathrm{~V}$ \\
KED voltage & $-10.0 \mathrm{~V}$ \\
Octopole bias voltage & $2.0 \mathrm{~V}$ \\
\hline
\end{tabular}




\section{Separation Procedure}

An amount of $20 \mathrm{~mL} 0.05 \mathrm{~mol} \mathrm{~L}^{-1}$ Cyanex 272 was placed into a 60 $\mathrm{mL}$ separating funnel, and a mixture of $20 \mathrm{~mL}$ of water $(\mathrm{pH}=4)$ and $2 \mathrm{~mL}$ of $\mathrm{KMnO}_{4}$ was added. Then $5 \mathrm{~mL}$ of sample solution was adjusted to $\mathrm{pH}=4$ with $2 \%(\mathrm{~m} / \mathrm{v})$ $\mathrm{NaOH}$ and $15 \mathrm{~mL}$ of buffer solution $(\mathrm{pH}=4)$ before $2 \mathrm{~mL}$ of $\mathrm{KMnO}_{4}$ solution was added. The sample solution was subsequently subjected to extraction for about 2 minutes, and the aqueous layer discarded. Finally, the organic layer was back-extracted with $10 \mathrm{~mL}$ 5\% (v/v) $\mathrm{HNO}_{3}$ for 5 minutes, and the aqueous solution collected for ICPMS/MS determination.

Blanks were prepared in exactly the same way as is listed in the sample procedure.

\section{RESULTS AND DISCUSSION}

Typical Interferences with ICPMS/MS for REE Determination

In our previous work (21), through a joint instrumental optimization of both the aerosol dilution based sample introduction system and the DRC ${ }^{\text {TM }}$ (Dynamic Reaction Cell ${ }^{\mathrm{TM}}$ ) coupled MS/MS detection system of ICP-MS/MS, some typical overlapping and polyatomic interferences on $\mathrm{La}, \mathrm{Pr}, \mathrm{Tb}$, $\mathrm{Gd}$, and $\mathrm{Yb}$ were greatly reduced by about $2 \sim 3$ orders of magnitude in comparison with those in ICPQMS; thus, the direct analysis of Ce compounds with $6 \mathrm{~N}$ purity was feasible. In this work, a similar optimization of the instrument was carried out to obtain the optimal operation conditions, in particular $\mathrm{La}, \mathrm{Pr}, \mathrm{Gd}$, and $\mathrm{Yb}$ were detected in $\mathrm{O}_{2}$ mass-shift mode (the first quadrupole Q1 was set to the mass of $\mathrm{M}^{+}$and the second quadrupole Q2 was set to the mass of $\mathrm{MO}^{+}$), while $\mathrm{Tb}$ was detected in $\mathrm{NH}_{3}$ mass-shift (Q1 was set to the mass of $\mathrm{Tb}^{+}$and $\mathrm{Q} 2$ was set to the mass of $\mathrm{TbNH}^{+}$). After that, the interference elimination effect was evaluated more deeply with elevated Ce matrix concentrations. As indicated in Table II, the interferences on Gd, $\mathrm{Tb}$, and $\mathrm{Yb}$ at higher Ce matrix concentrations were not negligible and constructed the major obstacles for the direct analysis of Ce compounds over $7 \mathrm{~N}$ purity, thus, matrix separation became necessary.

For other REEs without interferences, the He collision mode was still selected to achieve collision focusing effects for higher analytical sensitivity.

Matrix Separation by Cyanex 272 Extraction

Thus, chemical separation of the matrix by solvent extraction was conducted. A relatively new extrac-

TABLE II

Evaluation of Interference Elimination Effects Under Optimized ICP-MS/MS Operating Cnditions

\begin{tabular}{ccccccc}
\hline Isotopes & \multicolumn{3}{c}{$\mathrm{O}_{2}$ Mass-shift } & \multicolumn{3}{c}{$\mathrm{NH}_{3}$ Mass-shift } \\
& $1280^{\mathrm{a}}$ & 640 & 320 & 1280 & 640 & 320 \\
\hline${ }^{139} \mathrm{La}$ & $0.052^{\mathrm{b}}$ & 0.032 & 0.014 & & & \\
${ }^{141} \mathrm{Pr}$ & 0.051 & 0.024 & 0.017 & & & \\
${ }^{160} \mathrm{Gd}$ & 0.249 & 0.069 & 0.038 & & & \\
${ }^{159} \mathrm{~Tb}$ & 1.086 & 0.506 & 0.269 & 0.324 & 0.155 & 0.072 \\
${ }^{172} \mathrm{Yb}$ & 0.128 & 0.042 & 0.019 & & & \\
\hline
\end{tabular}

${ }^{\mathrm{a}}$ Ce concentrations, $\mathrm{mg} \mathrm{L}^{-1}$.

$\mathrm{b}$ The apparent concentrations of the analytes, $\mu \mathrm{g} \mathrm{L}^{-1}$.

\section{Atomic Apectroscopy \\ 1 Vol. 40(5), Sept./Oct. 2019}

tion reagent of Cyanex 272 was investigated for the first time, and was compared with EHEHP as reported in the literature (17). As an acidic extractant, the extraction of the metal ions with Cyanex 272 could be expressed as follows:

$$
\begin{aligned}
& {\left[\mathrm{Ln}^{\mathrm{m}+}\right]_{\mathrm{a}}+\mathrm{m}\left[\mathrm{H}_{2} \mathrm{~A}_{2}\right]_{\mathrm{o}}=} \\
& {\left[\operatorname{Ln}\left(\mathrm{HA}_{2}\right)_{\mathrm{m}}\right]_{\mathrm{o}}+\mathrm{m}\left[\mathrm{H}^{+}\right]_{\mathrm{a}}}
\end{aligned}
$$

where $\left[\mathrm{Ln}^{\mathrm{m}+}\right]_{\mathrm{a}}$ is the concentration of the metal ion in the aqueous phase and $\left[\mathrm{H}_{2} \mathrm{~A}_{2}\right]_{\mathrm{o}}$ is the concentration of Cyanex 272 in the organic phase. It is well known that metal ions with larger charge number $\left(\mathrm{m}^{+}\right)$had stronger affinity with the extractant. So, if the matrix Ce(III) was previously oxidized to Ce(IV), then by applying extraction and back-extraction at different acidity in sequence, high separation efficiency could be obtained; for example, at low acidity, both Ce(IV) and REE(III) in the aqueous solution could be easily extracted into the organic phase, then with an increase of the acidity to a proper value, only REE(III) could be backextracted into the aqueous phase, while leaving Ce(IV) in the organic phase due to its much higher combining energy with Cyanex 272.

\section{Effect of pH on Extraction of REE(III)s}

As mentioned above, it was desirable for Cyanex 272 to operate at low acidic aqueous solutions for metal ion extraction and the extraction efficiency was $\mathrm{pH}$-sensitive. Following the literature (17), the ratio of organic phase volume to aqueous phase volume was fixed at $1: 1$, and the extractant concentration in the organic phase was set at $0.05 \mathrm{~mol} \mathrm{~L}^{-1}$. For a $10 \mathrm{ng} \mathrm{L}^{-1}$ of REE solution, two different $\mathrm{pH}$ values of 3 (adjusted with the monochloro-acetic acid buffer solution) and 4 (adjusted with the acetate buffer solution) were tested for their effects on the extraction efficiencies. As the results in Figure 1 show, $\mathrm{pH} 4$ was more effective for 
guaranteeing that all the extraction efficiencies for the REEs were over $90 \%$. Higher $\mathrm{pH}$ values were not tested since precipitation of the REEs would occur, so the optimal extraction acidity was set at $\mathrm{pH} 4$.

Optimization of $\mathrm{KMnO}_{4}$ Amount and Extraction Time

It was proved that $\mathrm{KMnO}_{4}$ was the most effective oxidant for $\mathrm{Ce}^{3+}$ at the optimized extraction $\mathrm{pH}$ value of 4 (17). It was important to optimize the amount of $\mathrm{KMnO}_{4}$ and the extraction time for a given sample amount in this work. Through experiments, we found that Cyanex 272 tended to react with $\mathrm{KMnO}_{4}$ more easily than EHEHP, which would result in more $\mathrm{MnO}_{2}$ solid particles (the reduction product) produced within a similar extraction duration. Consequently, emulsification would occur more easily at the organic/water interface, thus increasing the difficulty of phase separation and the risk of analyte loss (even up to $80 \%$ ), therefore, a large amount of $\mathrm{KMnO}_{4}$ for the concentration of $\mathrm{Ce}$ is not suitable for the separation. So, we conducted a series of exploratory experiments to avoid emulsification, such as appropriately reducing the dosage of $\mathrm{KMnO}_{4}$, strictly controlling the oscillation intensity, and shortening the extraction time as far as possible. It was found that for

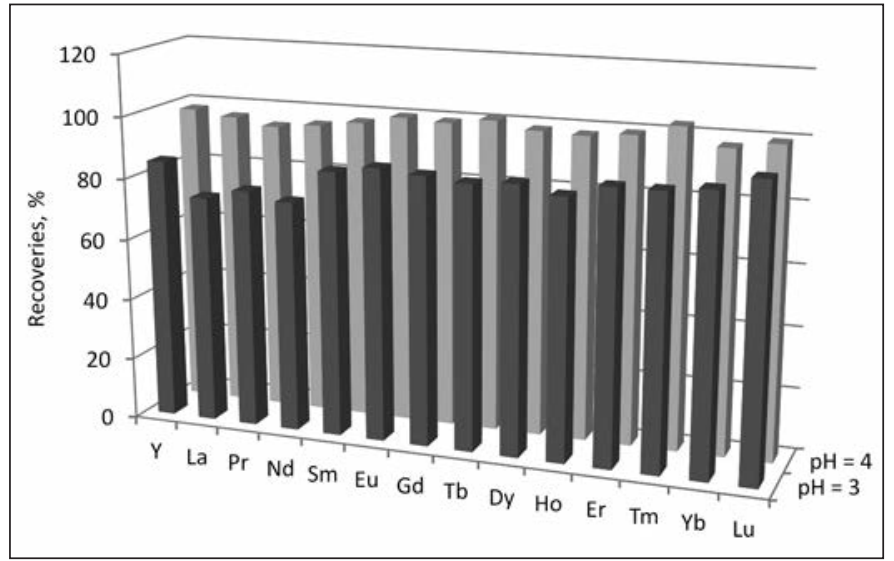

Fig. 1. Effect of $p H$ values on the extraction efficiencies of REE(III)s. a $0.1 \mathrm{~g}$ of sample, $10 \mathrm{mg}$ amount of $\mathrm{KMnO}_{4}$ at the extraction $\mathrm{pH}$ of 4 and extraction duration of 2 minutes by manually shaking the vial could increase not only the oxidation efficiency by more than $99.99 \%$ for $\mathrm{Ce}^{3+}$, but also result in a complete extraction of both the Ce matrix and the REE analytes.

Optimization of Acidity and Time for Back-extraction

It is well known that heavy REEs are more difficult to back-extract than light REEs with phosphonic acid extractants. As stated in the literature (17), back-extraction with $10 \%(\mathrm{v} / \mathrm{v}) \mathrm{HNO}_{3}$ was required to be done twice for the recovery of all REEs over 90\% when EHEHP was used as the extractant. Therefore, the whole analytical procedure became more tedious and complicated, and the separation efficiency of the Ce matrix was reduced since more $\mathrm{Ce}^{4+}$ ions were simultaneously back-extracted.

In this work, different concentrations of $\mathrm{HNO}_{3}$ solutions of $10 \mathrm{~mL}$ were investigated to observe their effects for all REEs. As seen in Figure 2, a single back-extraction with $5 \%(\mathrm{v} / \mathrm{v})$ of $\mathrm{HNO}_{3}$ was enough even for the complete back-extraction of all of the heavy REEs. And in order to prevent the reduction of $\mathrm{Ce}^{4+}$ by the organic substance under acidic conditions, the back-extraction time should, therefore, be as short as possible. It was found that manually shaking the vial for about 5 minutes was enough for a complete extraction of all of the analytes.

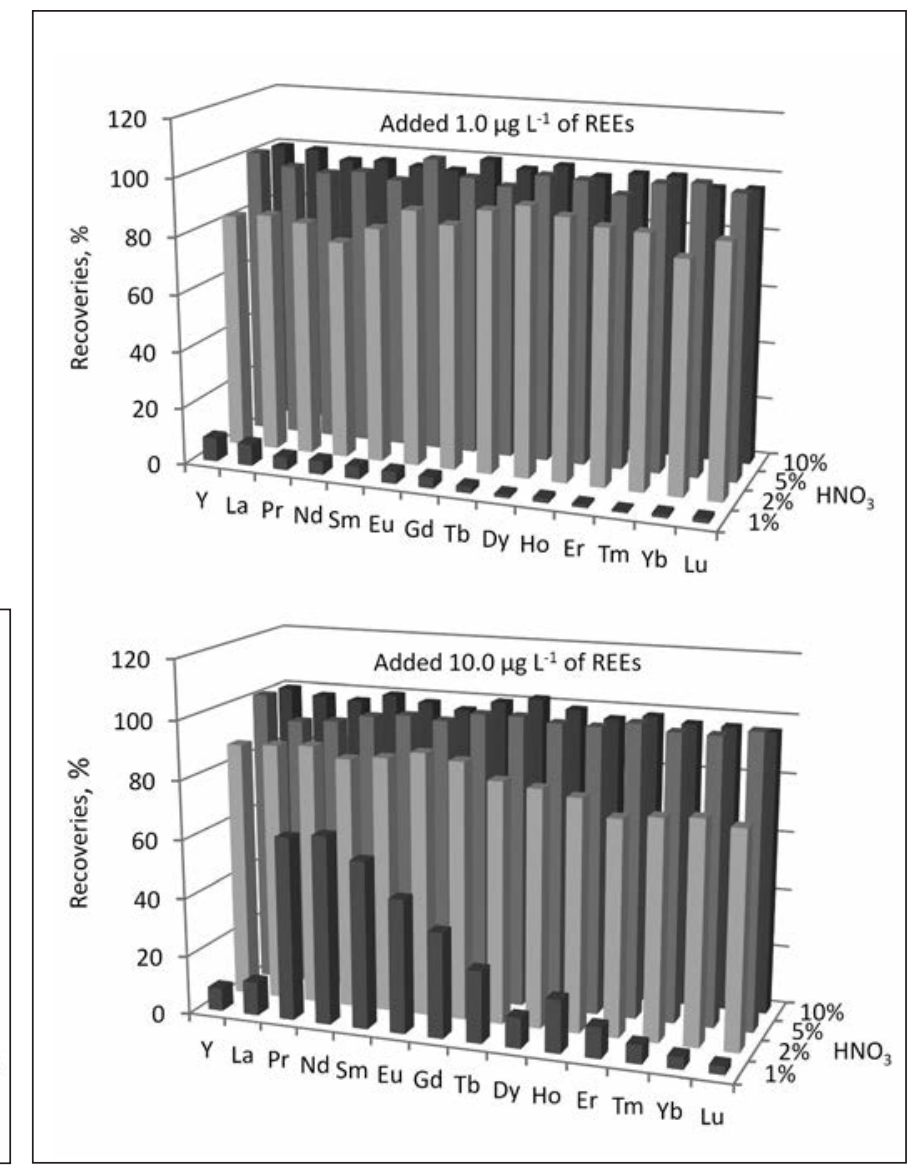

Fig. 2. Effect of acidity on the back-extraction efficiencies of all REE analytes. 
Matrix Separation Efficiency Evaluation

To assess the matrix separation efficiency, the concentration of Ce remaining in the aqueous phase after back-extraction was determined. The separation efficiency was defined as $\left(1-\left(\mathrm{C}_{1} \times \mathrm{V}_{1} / \mathrm{C}_{0} \times \mathrm{V}_{0}\right)\right)$ $\times 100 \%$, where $C_{1}$ was the remaining Ce concentration in the final back-extraction solution, $\mathrm{V}_{1}$ was the volume of the final back-extraction aqueous solution $(10 \mathrm{~mL}), \mathrm{C}_{0}$ was the original Ce concentration in the aqueous solution prior to extraction, $\mathrm{V}_{0}$ was the volume of the aqueous solution prior to extraction $(5 \mathrm{~mL})$. The results of repeated tests in Table III show much higher separation efficiencies obtained in this work than those reported in the literature with EHEHP (17). So, in combination with the strong function of ICPMS/MS for polyatomic interference elimination, ultra-high matrix separation efficiencies would help realize a truly interference-free determination of all of the ultra-trace

TABLE III

Matrix Separation Efficiencies of Five Replicate Separations

\begin{tabular}{llll}
\hline $\begin{array}{c}\text { Sample } \\
\text { No. }\end{array}$ & $\begin{array}{c}\text { Original Ce } \\
\text { Concentrations } \\
\mathrm{C}_{0} / \mathrm{mg} \mathrm{L}^{-1}\end{array}$ & $\begin{array}{c}\text { Remaining Ce } \\
\text { Concentrations } \\
\mathrm{C}_{1} / \mathrm{mg} \mathrm{L}^{-1}\end{array}$ & $\begin{array}{c}\text { Separation } \\
\text { Efficiencies } \\
(\%)\end{array}$ \\
\hline 1 & 332.6 & 0.0832 & 99.95 \\
2 & 332.8 & 0.0836 & 99.95 \\
3 & 332.8 & 0.0954 & 99.94 \\
4 & 332.5 & 0.0870 & 99.95 \\
5 & 332.8 & 0.0846 & 99.95 \\
Average & 332.7 & 0.0868 & 99.95 \\
\hline
\end{tabular}

TABLE IV

Recoveries of Spiked Test and Limits of Detection for the Method

\begin{tabular}{cccl}
\hline \multirow{2}{*}{ Element } & \multicolumn{2}{l}{ Spiked Recovery Test (\%) } & \\
\cline { 2 - 3 } & $1.0 \mu \mathrm{g} \mathrm{L}^{-1}$ & $10.0 \mu \mathrm{g} \mathrm{L}^{-1}$ & \\
\cline { 2 - 3 } $\mathrm{Y}$ & 98.3 & 96.5 & 0.24 \\
$\mathrm{La}$ & 92.8 & 93.6 & 0.042 \\
$\mathrm{Pr}$ & 95.5 & 98.2 & 0.18 \\
$\mathrm{Nd}$ & 94.6 & 95.2 & 0.33 \\
$\mathrm{Sm}$ & 97.8 & 94.8 & 0.30 \\
$\mathrm{Eu}$ & 96.9 & 103 & 0.19 \\
$\mathrm{Gd}$ & 97.8 & 98.6 & 0.44 \\
$\mathrm{~Tb}$ & 98.6 & 96.8 & 0.13 \\
$\mathrm{Dy}$ & 97.9 & 100 & 0.11 \\
$\mathrm{Ho}$ & 97.9 & 99.8 & 0.24 \\
$\mathrm{Er}$ & 98.7 & 94.2 & 0.33 \\
$\mathrm{Tm}$ & 98.6 & 98.7 & 0.013 \\
$\mathrm{Yb}$ & 96.0 & 96.3 & 0.30 \\
$\mathrm{Lu}$ & 99.8 & 98.6 & 0.12 \\
\hline
\end{tabular}

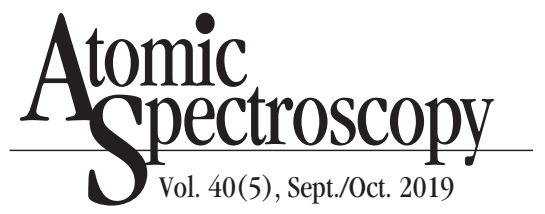

REE impurities.

Method Evaluation and Real Sam-
ple Analysis

The validity of the proposed method was demonstrated by the separation and analysis of a spiked sample. A spiked test for the whole analytical procedure was carried out and the results for different spiked levels were satisfactory, as listed in Table IV. The limits of detection (LOD, 3 $\sigma$ ) for all of the analytes were calculated as three times the standard deviation of 11 blank measurements, ranging from 0.013 to $0.44 \mathrm{ng} \mathrm{g}^{-1}$ for the liquid solution (also listed in Table IV). The data suggests that the accuracy and precision are satisfactory and the quantification limits allow the determination of 14 REE impurities in $7 \mathrm{~N}$ cerium chealate. Finally, the method was applied for the analysis of three Ce(TMHD) ${ }_{4}$ samples, claimed of $99.99999 \%$ purity, and the results are listed in Table V.

\section{CONCLUSION}

The combination of chemical
TABLE V

Real Sample Analysis ( $\mathrm{n}=3)$

\begin{tabular}{lllllll}
\hline $\begin{array}{l}\text { Ele- } \\
\text { ment }\end{array}$ & $\begin{array}{c}\text { Sample } 1 \\
\text { Content } \\
\left(\mu \mathrm{g} \mathrm{g}^{-1}\right)\end{array}$ & $\begin{array}{l}\text { RSD } \\
(\%)\end{array}$ & $\begin{array}{c}\text { Sample } 2 \\
\text { Content } \\
\left(\mu \mathrm{g} \mathrm{g}^{-1}\right)\end{array}$ & $\begin{array}{l}\text { RSD } \\
(\%)\end{array}$ & $\begin{array}{c}\text { Sample } 3 \\
\text { Content } \\
\left(\mu \mathrm{g} \mathrm{g}^{-1}\right)\end{array}$ & $\begin{array}{l}\text { RSD } \\
(\%)\end{array}$ \\
\hline $\mathrm{Y}$ & $\mathrm{ND}^{\mathrm{a}}$ & $-\mathrm{b}$ & $\mathrm{ND}$ & - & $\mathrm{ND}$ & - \\
$\mathrm{La}$ & $\mathrm{ND}$ & - & $\mathrm{ND}$ & - & $\mathrm{ND}$ & - \\
$\mathrm{Pr}$ & 0.013 & 1.2 & 0.016 & 1.6 & 0.016 & 1.2 \\
$\mathrm{Nd}$ & $\mathrm{ND}$ & - & 0.012 & 2.3 & 0.012 & 2.4 \\
$\mathrm{Sm}$ & $\mathrm{ND}$ & - & $\mathrm{ND}$ & - & $\mathrm{ND}$ & - \\
$\mathrm{Eu}$ & $\mathrm{ND}$ & - & $\mathrm{ND}$ & - & $\mathrm{ND}$ & - \\
$\mathrm{Gd}$ & 0.015 & 0.7 & 0.023 & 2.8 & 0.020 & 2.4 \\
$\mathrm{~Tb}$ & 0.029 & 1.3 & 0.029 & 1.8 & 0.030 & 2.6 \\
$\mathrm{Dy}$ & $\mathrm{ND}$ & - & 0.013 & 3.6 & 0.010 & 4.2 \\
$\mathrm{Ho}$ & $\mathrm{ND}$ & - & $\mathrm{ND}$ & - & $\mathrm{ND}$ & - \\
$\mathrm{Er}$ & $\mathrm{ND}$ & - & $\mathrm{ND}$ & - & $\mathrm{ND}$ & - \\
$\mathrm{Tm}$ & $\mathrm{ND}$ & - & $\mathrm{ND}$ & - & $\mathrm{ND}$ & - \\
$\mathrm{Yb}$ & 0.010 & 3.3 & 0.017 & 2.0 & 0.013 & 2.2 \\
$\mathrm{Lu}$ & $\mathrm{ND}$ & - & $\mathrm{ND}$ & - & $\mathrm{ND}$ & - \\
\hline
\end{tabular}

${ }^{\mathrm{a}}$ Not Detected. $\quad{ }^{\mathrm{b}}$ Not Calculated. 
separation with triple quadrupole inductively coupled plasma mass spectrometry provided a high sensitive and truly interference-free method for the determination of REE impurities in Ce compounds with extremely high purity. The use of Cyanex 272, instead of EHEHP for the purpose of matrix Ce separation, possessed the merits of much higher separation efficiencies and more concise operation.

\section{ACKNOWLEDGMENT}

The authors are grateful for the financial support by the National Natural Science Foundation of China (No.21702194)

Received July 19, 2019.

\section{REFERENCES}

1. E. H. Sekiya, P. Barua, K. Saito, and A. J. Ikushima, J. Non-Cryst. Solids 4347(42-44), 354 (2008).

2. A. J. Boyland, A. S. Webb, S. Yoo, F. H. Mountfort, M. P. Kalita, R. J. Standish, J. K. Sahu, D. J. Richardson, and D. N. Payne, J. Lightwave Technol. 912(6), 29 (2011).

3. M. Engholm, P. Jelger, F. Laurell, and L. Norin, Optics Lett. 1285(8), 34 (2009).

4. Y. Xu, D. Chen, S. Li, L. Hu, and J. Tang, J. Inorg. Mater. 240(3), 30 (2015).

5. T. Shi, Z. Zhou, L. Ni, X. Xiao, H. Zhan, A. Zhang, and A. Lin, Appl. Optics 3191(15), 53 (2014).

6. G. Ruan, Chin J. Inorg. Anal. Chem. 15(4), 1 (2011).

7. S. Chen and Z. He, Anal. Test. Technol. Instrum. 217(4), 17 (2011).

8. J. Ning, Chin. J. Spectrosc. Lab. 947(2), 30 (2013)

9. N. Shitaba, N. Fudagawa, and M. Kubota, Anal. Chem. 636(6), 63 (1991)

10. L. Balcaen, E. Bolea-Fernandez, M. Resano, and F. Vanhaecke, Anal. Chim. Acta 7, 894 (2015).
11. S. D. Fernandez, N. Sugishama, and J. R. Encinar, and A. Sanz-Medel, Anal. Chem. 5851(14), 84 (2012).

12. W. Guo, L. L. Jin, S. H. Hu, and Q. H. Guo, J. Agric. Food Chem. 65, 3406 (2017).

13. J. Li, X. Wu, and Y. Zheng, Journal of Instrumental Analysis 32(4), 24 (2005).

14. W. Wu, H. Liu, and T. Zheng, Chin. J. Anal. Chem. 697(5), 43 (2015).

15. K. Kawabata, Y. Kishi, O. Kawaguchi, Y. Watanabe, and Y. Inoue, Anal. Chem. 2137(19), 63 (1991).

16. T. Duan, H. Li, J. Kang, and H. Chen, Anal. Sci. 921(6), 20 (2004).

17. B. Li, Y. Zhang, and M. Yin, Analyst 543(6), 122 (1997).

18. M. I. Saleh, M. F. Bari, and B. Saad, Hydrometallurgy 75(1), 63 (2002).

19. E. Kashi, R. Habibpour, H. Gorzin, and A. Maleki, J. Rare Earths 317(3), 36 (2018).

20. H. Matsuyama, A. Azis, M. Fujita, and $M$. Teramoto, J. Chem. Eng. Jpn. 126(1), 29 (1996).

21. Y. Zhang, Z. Pan, P. Jiao, J. Ju, T. He, and H. Cai, J. Instrumental Analysis 304(3), 38 (2019). 